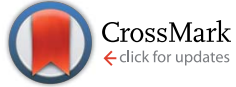

Cite this: RSC Adv., 2015, 5, 50063

Received 8th May 2015

Accepted 28th May 2015

DOI: $10.1039 / \mathrm{c} 5 \mathrm{ra06697b}$

www.rsc.org/advances

\section{Precursor-controlled and template-free synthesis of nitrogen-doped carbon nanoparticles for supercapacitors $\uparrow$}

\author{
Li-Ping Lv, ${ }^{a}$ Zhong-Shuai Wu, ${ }^{a}$ Long Chen, ${ }^{\mathrm{b}}$ Hao Lu, ${ }^{a}$ Yi-Ran Zheng, ${ }^{a}$ Tobias Weidner, ${ }^{a}$ \\ Xinliang Feng, ${ }^{a}$ Katharina Landfester ${ }^{a}$ and Daniel Crespy ${ }^{\star a}$
}

\begin{abstract}
We describe the synthesis of hierarchical porous nitrogen-doped carbon nanoparticles with high specific surface area and specific capacitance for supercapacitors. Octapyrrolylnaphthalene (OPN) with eight substituent pyrrolyl groups is used as a reaction precursor and the oxidative product, assigned as POPN, is synthesized in miniemulsion droplets. Further carbonization of POPN at $600{ }^{\circ} \mathrm{C}$ (POPN600) and $800^{\circ} \mathrm{C}$ (POPN800) provides particles with hierarchical porosity, well-defined nanoparticle structure, and high specific surface area. The obtained nitrogen-doped carbon particles POPN800 exhibit a specific capacitance of $156 \mathrm{~F} \mathrm{~g}^{-1}$ at the scan rate of $2 \mathrm{mV} \mathrm{s}^{-1}$ and $80 \mathrm{~F} \mathrm{~g}^{-1}$ when the scan rate increases to $100 \mathrm{mV} \mathrm{s}^{-1}$. The high specific capacitance and excellent rate capability can be attributed to the controlled structure of the nanoparticles, hierarchical micro- and mesoporosity, high surface area $\left(365 \mathrm{~m}^{2} \mathrm{~g}^{-1}\right)$, and rich nitrogen-doping. The present method allows therefore for the synthesis of nitrogen-doped carbon materials for supercapacitors in an easy one-pot and template-free miniemulsion procedure followed by carbonization.
\end{abstract}

\section{Introduction}

Supercapacitors for energy storage attract increasing attention due to their high energy and power densities. Up to now, research for supercapacitors mainly focuses on developing electrode materials that play a crucial role on the performance of supercapacitors. ${ }^{1-3}$ The most studied electrode materials are carbon-based materials due to their low cost, various existing forms, as well as their good stability and electric conductivity. ${ }^{4-7}$ The specific capacitance of supercapacitors is strongly influenced by the surface area of the carbon electrodes in contact with the electrolyte ions. ${ }^{8}$ The larger the surface area of the carbons, the more charges will accumulate to the electrode/ electrolyte interface. Therefore, porous carbon electrodes with high surface areas are highly interesting. Moreover, a hierarchical porous property of electrode materials has been proved to provide distinctive performance for the supercapacitors. Electrode materials with macro-/meso- ${ }^{9}$ macro-/micro- ${ }^{11}$ meso-/ micro- ${ }^{12}$ or macro-/meso-/micropores ${ }^{13}$ are widely reported. The macro- or mesopores are reported to promote charge

${ }^{a}$ Max Planck Institute for Polymer Research, Ackermannweg 10, 55128 Mainz, Germany.E-mail: crespy@mpip-mainz.mpg.de

${ }^{b}$ Department of Chemistry, School of Science, Tianjin University, 300072 Tianjin, China

$\dagger$ Electronic supplementary information (ESI) available: ${ }^{1} \mathrm{H}$ NMR spectrum of OPN; XPS survey spectra of POPN, POPN600 and POPN800; electron micrographs of POPN nanoparticles. See DOI: 10.1039/c5ra06697b propagation to the bulk of the electrode materials while the micropores can provide effective surface area to obtain high charge storage. ${ }^{\mathbf{1 0}}$

Using templates such as special nanostructures, researchers have already succeeded in synthesizing carbon materials with hierarchical porosities via $\operatorname{hard}^{\mathbf{1 3 - 1 5}}$ or $\mathrm{soft}^{\mathbf{1 6 , 1 7}}$ template methods. The template-assisted procedures require one or several additional steps to prepare the template itself. Several procedures for the preparation of nitrogen-doped carbon spheres for supercapacitors were reported. Nitrogen containing polymers were adsorbed or synthesized on hard templates such as silica, ${ }^{18,19}$ calcium acetate, ${ }^{20}$ polystyrene based particles ${ }^{21,22}$ and subsequently carbonized. Another possibility is the direct carbonization of crosslinked polymer particles ${ }^{23-25}$ or porous organic frameworks. ${ }^{26}$ Another strategy was based on the low temperature defluorination of poly(vinylidene fluoride) particles with an organic alkali treatment followed by high temperature carbonization. ${ }^{27}$ Finally, a dual-templating approach involved phenolic resol as a carbon source, and a block copolymer surfactant and spherical silica mesocellular foams as soft and hard template. ${ }^{28}$

Miniemulsion polymerization is known to be a versatile method to prepare various nanostructures. Each of the miniemulsion droplets can act as an individual batch reactor stabilized against Ostwald ripening and coalescence, ${ }^{29}$ hence allowing a wide range of possibilities of reactions, including reactions for which the absence of water is suitable. ${ }^{30-32}$ Thus, mesoporous silica particles and capsules with high specific 
surface area were already synthesized by the miniemulsion technique..$^{33,34}$

Herein, using the miniemulsion technique, we present a one-pot and template-free method to synthesize nitrogen-rich porous carbon-based electrode material for high-performance supercapacitors. A pyrrolyl-naphthalene derivative OPN is used as precursor and dissolved in miniemulsion droplets. After oxidation of OPN (the product after oxidative reaction of OPN was assigned as POPN) and evaporation of the solvents from the droplets, porous carbon-rich precursor nanoparticles are generated. Upon further thermal treatment at high temperature, the formed carbon nanoparticles exhibit a hierarchical porosity, i.e. coexistence of mesopores and micropores.

Previous studies showed that heteroatoms such as oxygen and nitrogen are advantageous for carbon-based electrode materials. ${ }^{35-37}$ Nitrogen-doped carbon materials, for example, were found to improve the specific capacitance of the electrode materials..$^{38-42}$ The nitrogen-functionalization was assumed to provide chemically active sites in the carbon frameworks and thus improve the electrochemical performance of supercapacitors. In the present work, a naphthalene derivative with eight pyrrolyl substituents was used as reaction precursor, providing the system simultaneous nitrogen-doping property.

Though a variety of carbon materials with nitrogen functionality were synthesized for supercapacitors, ${ }^{8,43-49}$ the preparation of nitrogen-doped carbon particles is seldom reported. ${ }^{18-28,50}$ However, the previously reported nitrogendoped carbon materials usually require templates to obtain a hierarchical porosity and a post-treatment to introduce the nitrogen functionality. We describe below a new method to prepare nanoparticles in a one-pot and template-free procedure.

\section{Experimental}

\section{Materials}

Sodium dodecyl sulfate (SDS, Sigma-Aldrich, 99\%), ammonium persulfate (APS, ACROS Organics, 98\%) and chloroform (ACROS Organics, 99\%) were used without further purification. Octapyrrolylnaphthalene (OPN) was synthesized according to the literature..$^{51}$ The ${ }^{1} \mathrm{H}$ NMR spectrum shown in Fig. S1 $\dagger$ displayed the characteristic peaks of OPN $\left(\mathrm{CDCl}_{3}, \delta, \mathrm{ppm}\right): 6.19(8 \mathrm{H}, \mathrm{m})$, $5.98(16 \mathrm{H}, \mathrm{m})$ and $5.82(8 \mathrm{H}, \mathrm{m})$. Distilled water was used throughout the work.

\section{Preparation procedures for porous POPN nanoparticles}

To prepare the oxidative product POPN nanoparticles, $100 \mathrm{mg}$ of OPN was dissolved in $2.1 \mathrm{~mL}$ of $\mathrm{CHCl}_{3}$ followed by mixing with $20 \mathrm{~mL}$ of aqueous solution of SDS $(200 \mathrm{mg})$. The mixture was first stirred at $1000 \mathrm{rpm}$ for $1 \mathrm{~h}$ at room temperature and then ultrasonicated with a sonifier (Branson W450D Digital, half inch tip) for $240 \mathrm{~s}$ ( $30 \mathrm{~s}$ plus, $15 \mathrm{~s}$ pause) at $90 \%$ amplitude with ice cooling. The oxidative reaction procedure was then carried out in an ice-water bath by dropwise addition of an aqueous solution of APS ( $1.36 \mathrm{~g}$ in $1.5 \mathrm{~mL}$ of water). The color of the dispersion turned from yellow to dark brown as the reaction proceeded. After $24 \mathrm{~h}$, the POPN nanoparticle dispersion was dialyzed against water for 3 days to remove the surfactant.

\section{Characterization}

Thermal gravimetric analysis (TGA) of POPN nanoparticles was carried out on a TGA 851 thermogravimetric analyzer with a heating rate of $5{ }^{\circ} \mathrm{C} \min ^{-1}$ in $\mathrm{N}_{2}$ atmosphere. The pyrolysis process was then performed in a furnace for $3 \mathrm{~h}$ at $600{ }^{\circ} \mathrm{C}$ or $800^{\circ} \mathrm{C}$ in $\mathrm{N}_{2}$ atmosphere. The sample after pyrolysis was assigned as POPN600 or POPN800, respectively. The FTIR spectra of OPN, POPN, POPN600, and POPN800 were measured on KBr pellets using a Perkin-Elmer spectrum BX FT-IR spectrometer. All spectra were collected in the range of $400-4000 \mathrm{~cm}^{-1}$ with a resolution of $1 \mathrm{~cm}^{-1}$. Elemental analysis (EA) of all samples was determined with a Heraeus CHN-rapid analyser (Hanau, Germany). The morphology of the particles were examined with a Gemini 1530 (Carl Zeiss AG, Oberkochem, Germany) scanning electron microscope (SEM) operating at $0.3 \mathrm{kV}$. Samples for SEM were prepared by dropping purified particle dispersions on silicon wafers and were dried at room temperature. The morphology of the particles was also studied using a transmission electron microscope (TEM) (JEM 1400, JEOL Ltd., Japan) operating at an accelerating voltage of $120 \mathrm{kV}$. All samples were deposited for their dispersion on a 300 mesh carbon-coated copper grid and dried at room temperature.

The surface area and pore size distribution of POPN, POPN600, and POPN800 were investigated by nitrogen adsorption and desorption at $-196{ }^{\circ} \mathrm{C}$ using Quadrasorb SI (Quantachrome Instruments). Prior to measurements, all the samples were degassed at $100{ }^{\circ} \mathrm{C}$ for $24 \mathrm{~h}$ under high vacuum. The data was evaluated by using the QuadraWin software from Quantachrome Instruments. The pore size distributions and pore volumes of samples were derived from the adsorption branches of the isotherms by using the Quenched Solid Density Functional Theory (QSDFT, $\mathrm{N}_{2}$, assuming carbon adsorbent with slit pores).

$\mathrm{X}$-ray photoelectron spectroscopy (XPS) was conducted using a Kratos Axis Ultra spectrometer (Kratos, Manchester, England) using an $\mathrm{Al} \mathrm{K} \alpha$ excitation source with a photon energy of $1487 \mathrm{eV}$. The data was acquired in the hybrid mode using a $0^{\circ}$ take-off angle, defined as the angle between the surface normal and the axis of the analyzer lens. Survey (Fig. S2 $\dagger$ ) and N 1s high-resolution (Fig. 3) spectra was collected with analyzer pass energy of $80 \mathrm{eV}$ and $20 \mathrm{eV}$, respectively. A charge neutralizer was always used during spectra collection to compensate charge build-up on the samples. The binding energy scale was calibrated using the main carbon peak at $284.8 \mathrm{eV}$ in $\mathrm{C} 1 \mathrm{~s}$ region.

Electrochemical measurements were carried out by a CHI760D electrochemical work station. CV measurements were performed in a three-electrode system. The working electrodes were prepared by mixing $80 \mathrm{wt} \%$ of POPN nanoparticles (4 mg), $10 \mathrm{wt} \%$ of acetylene black, and $10 \mathrm{wt} \%$ of polytetrafluoroethylene (PTFE) binder dispersed in ethanol solvent, and then pressed on a platinum mesh network serving as a current collector. A platinum plate was used as counter electrode and a saturated calomel electrode (SCE) was used as reference electrode. $6 \mathrm{M} \mathrm{KOH}$ was used as aqueous electrolyte. 


\section{Results and discussion}

The POPN nanoparticles were prepared by the oxidative treatment of OPN molecules in miniemulsion droplets as illustrated in Scheme 1a. A dispersed phase containing the solid OPN and chloroform was first mixed with a continuous phase composed of surfactant and water. After the miniemulsification process, OPN/chloroform droplets stabilized by surfactants were formed. Oxidation of OPN started after an aqueous solution the oxidizing agent ammonium persulfate was added. The color of the miniemulsion dispersion gradually changed from yellow to dark brown as the reaction proceeded, indicating the formation of the oxidation product. The obtained product after reaction was then collected and purified by dialyzing against water followed by freeze-drying.

The oxidation of OPN, according to previous studies ${ }^{52,53}$ is assumed to involve an intermolecular polymerization together with an intramolecular cyclodehydrogenation process. ChaneChing et al. ${ }^{52}$ investigated the oxidation process of a series of dipyrrolyl molecules with different flexible and bulky spacers. According to their findings, the oxidation of those molecules with two proximal pyrrolyl rings involved both intramolecular and intermolecular coupling process and tended to form polymers with different structures. ${ }^{52}$ However, in the case of the hexapyrrolyl molecules reported by Lazerges et al. ${ }^{53}$ in which the benzene is substituted by several pyrrolyl residues, intramolecular coupling was also suggested but no dimer or polymer products were observed. Considering the structural analogy between OPN and hexapyrrolylbenzene (HPyB), we assume that the adjacent pyrrolyl residues of each OPN molecule also undergo an intramolecular coupling reaction. Nevertheless, an intermolecular polymerization process cannot be excluded as suggested by another study. ${ }^{\mathbf{6 0}} \mathrm{HPyB}$ was investigated for its a)

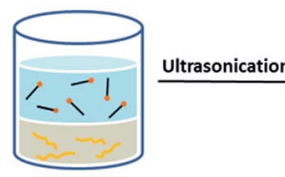

- Sodium dodecyl sulfate (SDS)

$\sim$ Octapyrrolylnaphthalene (OPN)

Water phase

b)

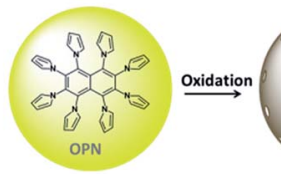

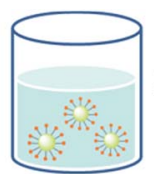
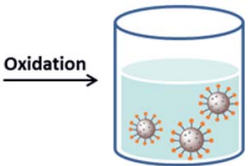

- Chloroform $\left(\mathrm{CHCl}_{3}\right)$ phase $\mathrm{OPN} / \mathrm{CHCl}_{3}$ droplet Porous POPN nanoparticle
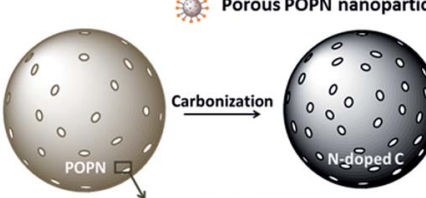
$\stackrel{\text { Carbonization }}{\longrightarrow}$

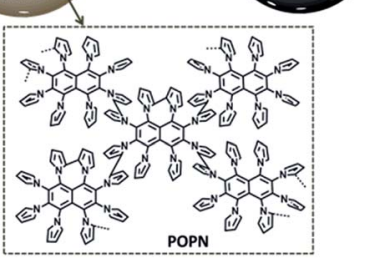

Scheme 1 (a) Illustration of the synthesis of porous POPN nanoparticles via the miniemulsion technique. (b) Reaction of OPN to form oxidative product POPN and schematic display of the procedure to prepare $\mathrm{N}$-doped porous carbon nanoparticles. electrochemical oxidation process. At least two redox couples were observed under repeated voltammetric scans during oxidation of HPyB in the region characteristic for pyrrole oligomers and polypyrrole. This observation indicated the complexity of the oxidation of HPyB where both intra- and intermolecular coupling is possible. ${ }^{60}$ The proposed chemical structure of oxidation product POPN is shown in Scheme $1 \mathrm{~b}$.

The morphology of POPN sample was then examined by electron microscopy. A multi-hollow structure was formed according to SEM and TEM micrographs (Fig. S3† and 1). This observation was attributed to two main reasons. Firstly, the rigid aromatic structure of OPN molecules led to a non-compact structure of the oxidation product POPN. Secondly, there is phase separation between chloroform and the formed POPN that occurs inside the miniemulsion droplets since the POPN is not soluble in the solvent. The removal of chloroform after the oxidation process generated porous structure in the formed POPN particles.

The chemical structure and thermal property of the POPN nanoparticles were further determined. As indicated in Fig. 2a, POPN showed peaks around $1100 \mathrm{~cm}^{-1}, 1300 \mathrm{~cm}^{-1}, 1400 \mathrm{~cm}^{-1}$ and $1600 \mathrm{~cm}^{-1}$ which were respectively attributed to the breathing vibrations of pyrrole rings, the $\mathrm{C}-\mathrm{N}$ stretching vibration in the ring and $\mathrm{C}-\mathrm{C}$ stretching vibrations in the pyrrole ring. After oxidation, the product POPN exhibited smoother peaks compared to that of OPN in which more fine structure of the peaks was observed. This observation is due to the intramolecular coupling and intermolecular polymerization of POPN after oxidation. Cyclodehydrogenation of OPN lead to a planar chemical structure for POPN, which consequently suppress bond vibrations such as the breathing vibrations of pyrrole

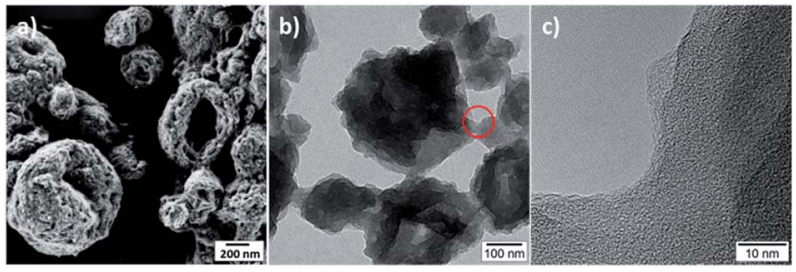

Fig. 1 SEM (a) and TEM micrographs of POPN nanoparticles with different magnification. (c) shows partial magnification of (b) as indicated in the red circle.
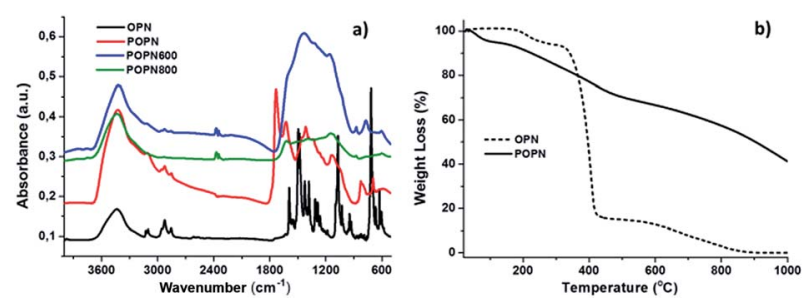

Fig. 2 (a) FT-IR spectra of OPN (black line), POPN (red line), POPN600 (blue line), and POPN800 (green line) after purification. (b) TGA curves of OPN (dashed line) and POPN nanoparticles (solid line) after purification. 
rings and the $\mathrm{C}-\mathrm{N}$ stretching vibration. However, compared to OPN, the FT-IR spectrum of POPN showed smoother peaks but not obvious weakening of the corresponding peaks assigned to the aforementioned bond vibrations, giving an indirect evidence for the possible existence of an intermolecular polymerization process. Therefore, the smoother peaks of POPN can be ascribed to the suppression of the bond vibrations caused by both the intramolecular and intermolecular coupling of OPN. TGA spectra gave another evidence of the carbon-rich feature of OPN as indicated in Fig. 2b. POPN exhibited only $\sim 60 \%$ of weight loss even when the handling temperature increased to $1000{ }^{\circ} \mathrm{C}$, indicating a high carbon yield for the POPN. In contrast, OPN started to show a significant weight loss when the handling temperature achieved $\sim 330{ }^{\circ} \mathrm{C}$. $\sim 85 \%$ of weight loss was already found when the temperature increased to $400{ }^{\circ} \mathrm{C}$. Almost no weight of the samples was left when temperature reached $1000{ }^{\circ} \mathrm{C}$. Therefore, both FTIR and TGA data gave a hint for the successful oxidation of OPN.

To produce nitrogen-doped carbon nanoparticles, the POPN nanoparticles were further carbonized in $\mathrm{N}_{2}$ atmosphere. A previous study suggested that the carbonization temperature plays an important role on the nitrogen species, nitrogen content and the pore structures of the final nitrogen-doped carbon nanofibers. ${ }^{40}$ Therefore, the POPN nanoparticles were carbonized at different temperature, i.e. $600{ }^{\circ} \mathrm{C}$ and $800{ }^{\circ} \mathrm{C}$ for $3 \mathrm{~h}$. The impact of the carbonization temperature on the nitrogen species, nitrogen content, and pore evolution of the resulting products POPN600 and POPN800 was then investigated. The electrochemical performance of these nitrogendoped carbon nanoparticles as electrode material for supercapacitor was also further studied in detail.

The FT-IR spectra of the samples POPN600 and POPN800 are shown in Fig. 2a. After carbonization, the chemical structure of both samples changed. Compared to the spectra of the POPN nanoparticles, the characteristic peaks of the pyrolyzed samples at around $1100 \mathrm{~cm}^{-1}, 1400 \mathrm{~cm}^{-1}$, and $1600 \mathrm{~cm}^{-1}$ merged into a broad peak, indicating a certain damage of the pyrrolyl rings in the sample. This observation became more obvious when the carbonization temperature increased from $600{ }^{\circ} \mathrm{C}$ to $800{ }^{\circ} \mathrm{C}$. A wide flat peak was found instead of a sharp peak in the sample POPN800. Elemental analysis data shown in Table 1 indicated an increase in the content of carbon and a decrease of hydrogen and sulfur after carbonization. This observation suggested the removal of compounds such as surfactants and doped species in the POPN samples prepared at elevated carbonization temperature. Meanwhile, the nitrogen content after carbonization did not exhibit much change, i.e. 14.5\% for POPN600 and $10.5 \%$ for POPN800 compared to $12.1 \%$ for POPN. The types of nitrogen existing in the samples, however, were found to differ as indicated by the XPS spectra (Fig. 3).

More detailed chemical information about the samples is provided by high-resolution scans of the $\mathrm{N} 1$ s region (Fig. 3a-c). The spectra were fitted with four peaks related to four distinct species of nitrogen: pyridinic nitrogen (N-6) near 398.3$398.8 \mathrm{eV}$, pyrrolic nitrogen ( $\mathrm{N}-5)$ near $400.0-400.7 \mathrm{eV}$, quaternary nitrogen (N-Q) near 401.0-401.6 eV and nitrogen oxides, nitro or nitroso groups (N-X) at higher binding energies (402.0-
Table 1 Elemental analysis and XPS data of POPN, POPN600 and POPN800 nanoparticles

\begin{tabular}{|c|c|c|c|c|c|c|c|c|}
\hline \multirow[b]{2}{*}{ Samples } & \multicolumn{4}{|c|}{ Element mass \% } & \multicolumn{4}{|c|}{$\begin{array}{l}\text { Deconvoluted peak of } \\
\text { nitrogen } \%\end{array}$} \\
\hline & $\mathrm{C}$ & $\mathrm{H}$ & $\mathrm{N}$ & S & $\mathrm{N}-5$ & $\mathrm{~N}-\mathrm{X}$ & N-6 & N-Q \\
\hline POPN & 53.2 & 4.3 & 12.1 & 2.7 & 50 & 50 & 0 & 0 \\
\hline POPN600 & 70.6 & 2.3 & 14.5 & 0 & 1.4 & 0 & 28 & 70.6 \\
\hline POPN800 & 75.0 & 1.6 & 10.5 & 0 & 0 & 0 & 30.2 & 69.8 \\
\hline
\end{tabular}

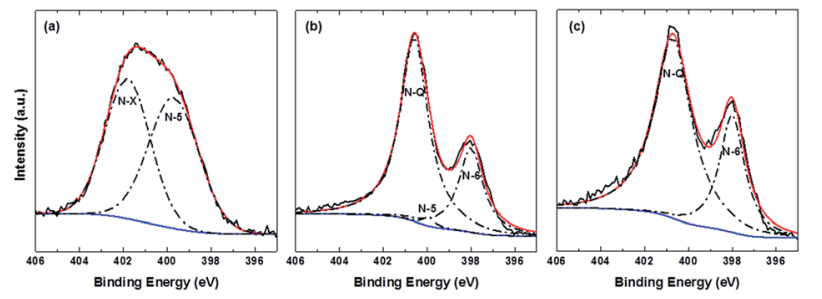

Fig. 3 Nitrogen 1s XPS spectra of POPN (a), POPN600 (b) and POPN800 (c) particles along with corresponding fits.

405.0 eV). ${ }^{54,55}$ Features at near 402.0-405.0 eV can also be caused by shake-up satellite peaks related to conjugated systems. ${ }^{56}$ The spectral fit shown in Fig. 3a reveals contributions from pyrrolic nitrogen and a second peak that could be related either to $\mathrm{N}-\mathrm{X}$ or the aromaticity of the particles. ${ }^{56}$ For the carbonized POPN600 particles the N-X related peaks were not detectable anymore while the N-5 feature was significantly decreased in intensity and two peaks assigned to N-6 and N-Q were observed (Fig. 3b). The N-6, N-Q and N-5 species had a relative concentration of $\sim 28 \%, 70.6 \%$ and $1.4 \%$, respectively. For the POPN800 sample the N-5 and N-X were absent in the spectra, leaving only N-6 and N-Q peaks as shown in Fig. 3c. The percentage of $\mathrm{N}-\mathrm{Q}(\sim 69.8 \%)$ was slightly decreased while $\mathrm{N}-6$ $(\sim 30.2 \%)$ increased compared to the POPN600 sample as summarized in Table 1. The existence of N-6 and N-Q in the carbon nanoparticles likely provides chemically active sites which can improve the performance of the electrode materials as previously suggested. ${ }^{39,40}$

The morphology of the nanoparticles after carbonization was also characterized as shown in Fig. S4 $\uparrow$ and 4 . Similar to POPN particles before carbonization (Fig. 1), rough and porous surfaces were also observed from SEM micrographs. TEM images further proved the porous interstitial structure, i.e. the existence of both mesopores (Fig. S4, $\uparrow$ a a and d) and micropores (Fig. 4c and f) in sample POPN600 and POPN800. Moreover, Fig. $4 \mathrm{c}$ and $\mathrm{f}$ also showed the existence of graphitic structures which leads to an improved electric conductivity. The size increase of the pyrolyzed POPN nanoparticles can be ascribed to the sintering and aggregating process caused by pyrolysis. Meanwhile, the mass loss due to the removal of surfactants and doped species upon high temperature leads to a decrease in size. This then results in a broad polydispersity of the pyrolyzed samples. To gain more information of the porosity of each sample, $\mathrm{N}_{2}$ adsorption/desorption isotherms were performed 


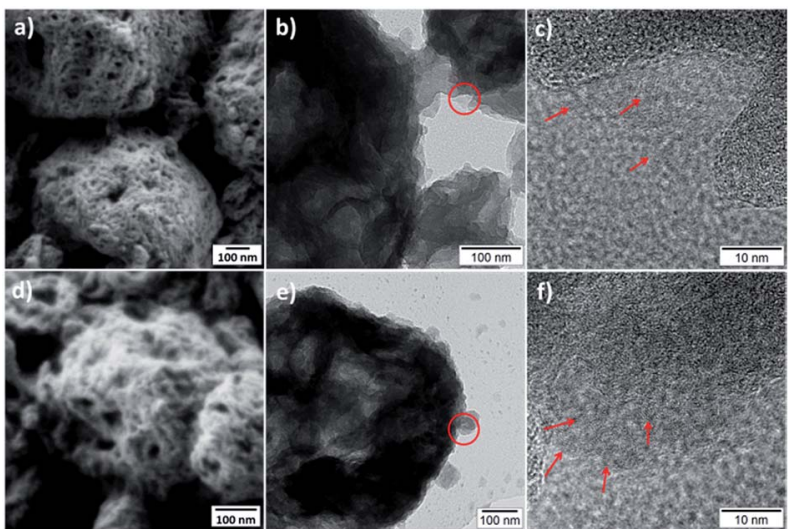

Fig. 4 SEM ( $a$ and $d$ ) and TEM (b, c, e and f) micrographs of POPN600 $(a-c)$ and POPN800 (d-f) nanoparticles. (c) and (f) show partial magnification of (b) and (e), as indicated in the red circles. The red arrows show the localized graphitic structures.

(Fig. 5a). The isotherm of sample POPN displays a small hysteresis loop at $P / P_{0}$ above 0.8 , which is associated with the existence of large mesopores. ${ }^{57}$ The two carbonized samples of both POPN600 and POPN800 exhibit isotherms close to type IV (according to IUPAC classification) which indicated the presence of both micropores ( $<2 \mathrm{~nm})$ and mesopores $(2-50 \mathrm{~nm})$ in the samples. ${ }^{40,57}$ The porous properties such as specific surface area, total pore volume, and the average pore diameter of these three samples are listed in Table 2. The specific surface area of POPN nanoparticles before carbonization was only $23 \mathrm{~m}^{2} \mathrm{~g}^{-1}$ but increased to $262 \mathrm{~m}^{2} \mathrm{~g}^{-1}$ and $365 \mathrm{~m}^{2} \mathrm{~g}^{-1}$ after carbonization at $600{ }^{\circ} \mathrm{C}$ and $800{ }^{\circ} \mathrm{C}$, respectively. Meanwhile, the average pore diameter was found to decrease from $14.6 \mathrm{~nm}$ (POPN) to $1.5 \mathrm{~nm}$ (POPN600 and POPN800). The smaller average pore diameter of POPN600 and POPN800 can be attributed to the removal of many non-carbon elements and carbon-containing species during the carbonization process. ${ }^{58}$ Fig. $5 \mathrm{~b}-\mathrm{d}$ exhibits the pore size distributions of the three samples, which were calculated
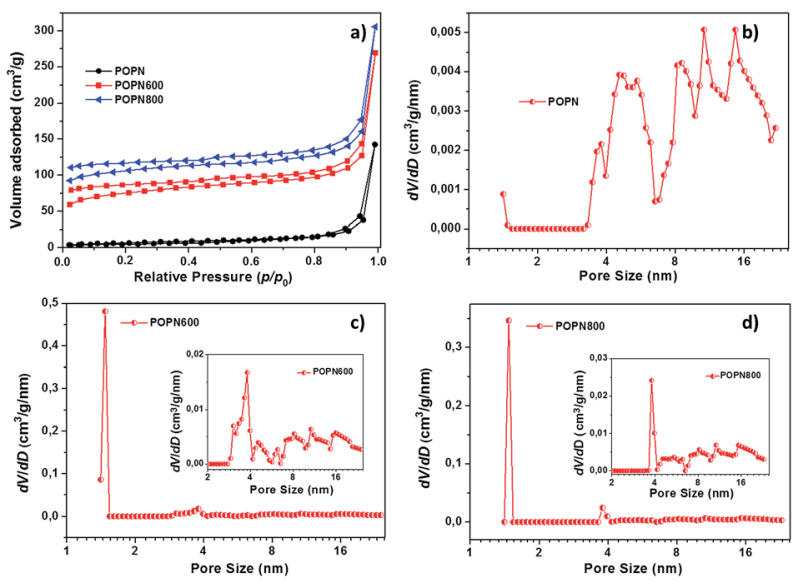

Fig. 5 Nitrogen adsorption-desorption isotherms (a) and pore size distribution of POPN (b), POPN600 (c) and POPN800 (d). Insert: magnified region $(2-25 \mathrm{~nm}$ ) of sample POPN600 and POPN800.
Table 2 Characteristics of pore structures of the porous POPN, POPN600, and POPN800 particles

\begin{tabular}{llll}
\hline Entry & $\begin{array}{l}\text { BET surface } \\
\text { area }\left(\mathrm{m}^{2} \mathrm{~g}^{-1}\right)\end{array}$ & $\begin{array}{l}\text { Total pore volume } \\
\left(\mathrm{cm}^{3} \mathrm{~g}^{-1}\right)\end{array}$ & $\begin{array}{l}\text { Average pore } \\
\text { size }(\mathrm{nm})\end{array}$ \\
\hline POPN & 22.8 & 0.062 & 14.6 \\
POPN600 & 262.2 & 0.202 & 1.5 \\
POPN800 & 365.3 & 0.248 & 1.5 \\
\hline
\end{tabular}

from the adsorption branches of the isotherms. Mesopores were only found in the non-carbonized sample. However, the samples POPN600 and POPN800 exhibited not only peaks around 3.8, 8.2, 10.7, $16.0 \mathrm{~nm}$ but also a sharp peak around $1.5 \mathrm{~nm}$, indicating the coexistence of mesopores and micropores in the samples. This observation explains the highly improved specific surface areas of POPN600 and POPN800 compared to POPN.

Given the advanced features of high specific surface area, hierarchical porosity, and high content nitrogen-doped nature, we further investigated the electrochemical performance of these N-doped porous carbon particles as electrode for supercapacitors, measured in three-electrode system with $6 \mathrm{M} \mathrm{KOH}$ aqueous electrolyte. As shown in Fig. 6a-c, the cyclic voltammetry (CV) profiles of POPN, POPN600, and POPN800 showed electrical double layer behavior at different sweeping rates. The possible reason for the distorted CV curves of POPN800 is the presence of a pseudocapacitive effect in the redox reaction due to the doped nitrogen in the carbon network. ${ }^{\mathbf{8}, 61}$ However, the specific capacitance of each sample was quite different as shown in Fig. 6d. The specific capacitance of POPN sample obtained at $2 \mathrm{mV} \mathrm{s}^{-1}$ was only $\sim 40 \mathrm{~F} \mathrm{~g}^{-1}$ but increased to $100 \mathrm{~F} \mathrm{~g}^{-1}$ after the sample was carbonized at $600{ }^{\circ} \mathrm{C}$ for $3 \mathrm{~h}$. Further increase of the carbonization temperature to $800{ }^{\circ} \mathrm{C}$ resulted in a good specific capacitance of $156 \mathrm{~F} \mathrm{~g}^{-1}$ at the scan rate of $2 \mathrm{mV} \mathrm{s}^{-1}$, almost 4 times as high as the untreated one. Moreover,
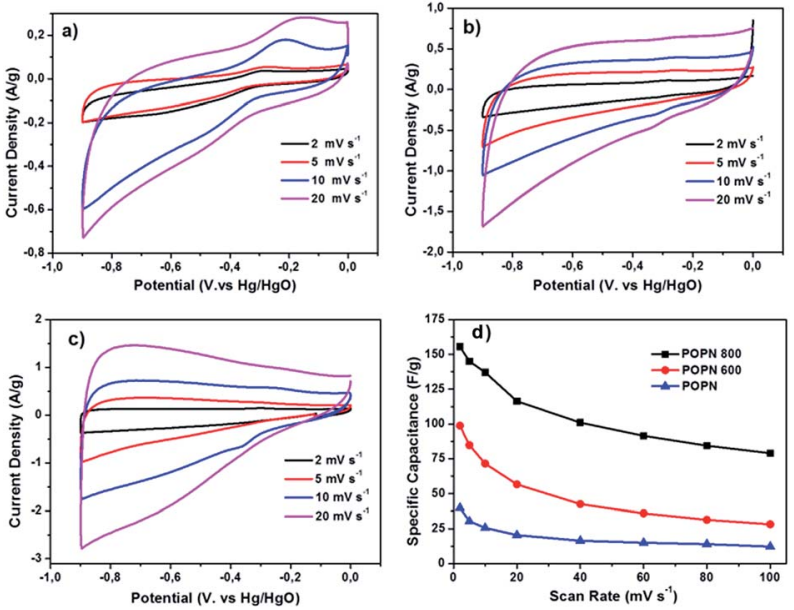

Fig. 6 Cyclic voltammetry of POPN (a), POPN600 (b) or POPN800 (c) measured at different scan rates $\left(\mathrm{mV} \mathrm{s}^{-1}\right)$ in $6 \mathrm{M} \mathrm{KOH}$ electrolyte. (d) Specific capacitance of POPN (blue line), POPN600 (red line) and POPN800 (black line) as a function of scan rate. 
even when the scan rate increased to $100 \mathrm{mV} \mathrm{s}^{-1}$, the specific capacitance of POPN800 was still $\sim 80 \mathrm{~F} \mathrm{~g}^{-1}$, which is much higher than POPN $\left(12 \mathrm{~F} \mathrm{~g}^{-1}\right)$ and POPN600 $\left(30 \mathrm{~F} \mathrm{~g}^{-1}\right)$, indicative of higher rate capability of POPN800.

Fig. 7a shows the galvanostatic charge/discharge curves of POPN800 electrode at different current densities. These curves exhibited a typical symmetric shape without obvious voltage drop, which is indicative of the fast ion diffusion in the bulk electrodes. Fig. 7b presents the specific capacitance of POPN800 electrode as a function of the current densities. POPN800 electrode exhibited specific capacitances of $132,84,67$, and $53 \mathrm{~F} \mathrm{~g}^{-1}$ at the corresponding current densities of $0.2,1,3$, and $5 \mathrm{~A} \mathrm{~g}^{-1}$, respectively. It should be noted that $40 \%$ of the initial capacitance at $0.2 \mathrm{~A} \mathrm{~g}^{-1}$ was kept even at high current density of $5 \mathrm{~A} \mathrm{~g}^{-1}$, suggesting an impressive rate capability. The electrochemical impendence spectroscopy was examined to investigate the fundamental electrochemical behavior of the POPN800 electrode, as shown in Fig. 7c. At low frequency, the curve is nearly perpendicular, indicating a good ideal capacitive behavior. Furthermore, the low equivalent series resistance of only $1.25 \mathrm{Ohm}$ and a small semicircle corresponding to low charge-transport resistance of $3.7 \mathrm{Ohm}$ were observed, which demonstrated a low internal resistance for the POPN800 electrode material. The cycling stability of POPN800 was also determined by galvanostatic charge-discharge measurement at $5 \mathrm{~A} \mathrm{~g}^{-1}$ in a $6 \mathrm{M} \mathrm{KOH}$ electrolyte. As shown in Fig. 7d, 99.7\% of the initial capacitance was retained after 5000 cycles, indicating excellent cycling stability of the POPN800 electrode.

The high specific capacitance and remarkable rate capability of POPN800 are attributed to the synergistic effect of controlled nanoparticle morphology, high specific surface
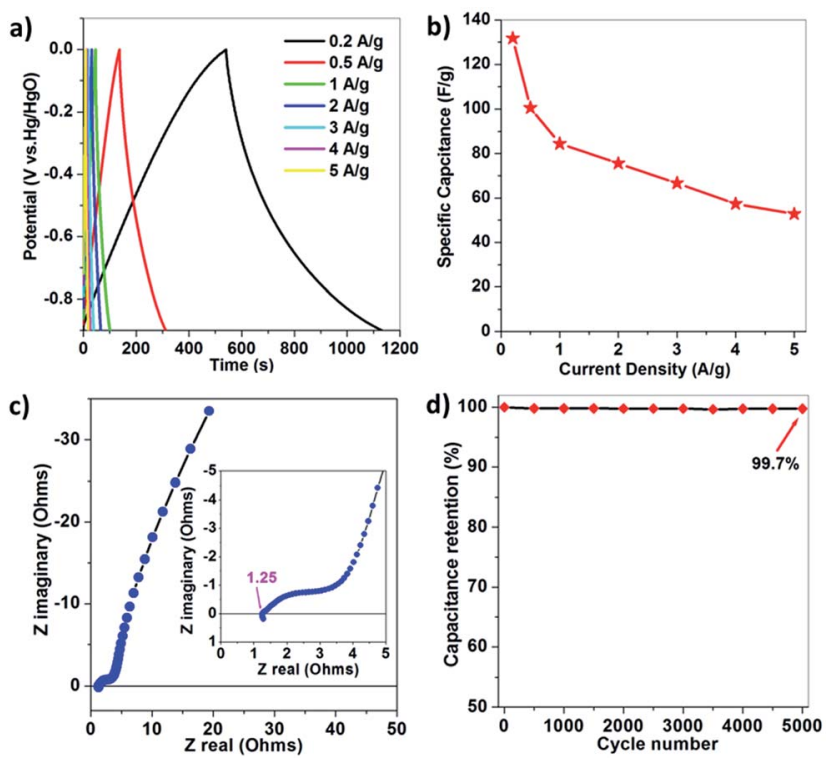

Fig. 7 (a) Galvanostatic charge-discharge curves of POPN800 electrodes at different current densities. (b) Specific capacitance of POPN800 electrode at different current densities. (c) Electrochemical impedance spectrum of POPN 800 electrode under the influence of an AC voltage of $5 \mathrm{mV}$. (d) Cycling ability of the POPN800 electrode measured at $5 \mathrm{~A} \mathrm{~g}^{-1}$ in a $6 \mathrm{M} \mathrm{KOH}$ electrolyte. area, hierarchical micro- and meso-porosity, and high nitrogen content, which work cooperatively together for the performance improvement in supercapacitors. First of all, after thermal treatment, the POPN800 with controlled nanoparticle structure and high surface area could increase the ion accessibility from the electrolyte to the surface of electrode, shorten ion transport pathway, and thus contribute to the better electrochemical properties. Secondly, nitrogen doping is considered as one of the most efficient strategies in the capacitance improvement when incorporated into the carbon framework. ${ }^{8}$ The presence of nitrogen species (N-6 and N-Q) in the system can provide various electrochemically active sites that significantly enhancing the performance of the supercapacitors. ${ }^{39,40}$ Thirdly, it was reported that for the hierarchical porous electrode material consisting of mesopores and micropores, the mesopores can provide accessible surface area for ion transport/ charge storage while the micropores play a role on the charge accommodation. ${ }^{\mathbf{1 0}}$ Therefore, the mesopores and micropores coexisting in the present system are considered to contribute together to high performance for supercapacitors. ${ }^{59}$

\section{Conclusions}

In summary, nitrogen-doped carbon nanoparticle as electrode material for supercapacitor were prepared by a facile and versatile method. After simple oxidative process of octapyrrolylnaphtalene in miniemulsion droplets, porous POPN nanoparticles were obtained. Further carbonization of POPN at different temperature provides the spheres with hierarchical porosity and improved specific surface area, as indicated by $\mathrm{N}_{2}$ adsorption/desorption measurements. The nitrogen-doped carbon spheres POPN800 exhibit a specific capacitance of $156 \mathrm{~F} \mathrm{~g}^{-1}$ at low scan rate and keep still $80 \mathrm{~F} \mathrm{~g}^{-1}$ when the scan rate increases to $100 \mathrm{mV} \mathrm{s}^{-1}$. The high specific capacitance of these porous carbon spheres can be attributed to the hierarchical porosity, high specific surface area as well as the nitrogen-doped effect.

\section{Acknowledgements}

We acknowledge Z.-J. Wang for the support with the measurements of $\mathrm{N}_{2}$ sorption isotherms.

\section{Notes and references}

1 P. Simon and Y. Gogotsi, Nat. Mater., 2008, 7, 845.

2 G. Wang, L. Zhang and J. Zhang, Chem. Soc. Rev., 2012, 41, 797.

3 A. S. Aricò, P. Bruce, B. Scrosati, J.-M. Tarascon and W. V. Schalkwijk, Nat. Mater., 2005, 4, 366.

4 E. Frackowiak and F. Béguin, Carbon, 2001, 39, 937.

5 A. G. Pandolfo and A. F. Hollenkamp, J. Power Sources, 2006, 157, 11.

6 Y. Zhu, S. Murali, M. D. Stoller, K. J. Ganesh, W. Cai, P. J. Ferreira, A. Pirkle, R. M. Wallace, K. A. Cychosz, M. Thommes, D. Su, E. A. Stach and R. S. Ruoff, Science, 2011, 332, 1537. 
7 L. L. Zhang and X. S. Zhao, Chem. Soc. Rev., 2009, 38, 2520.

8 E. Frackowiak, Phys. Chem. Chem. Phys., 2007, 9, 1774.

9 C. Yuan, X. Zhang, L. Su, B. Gao and L. Shen, J. Mater. Chem., 2009, 19, 5772.

10 Z.-S. Wu, Y. Sun, Y.-Z. Tan, S. Yang, X. L. Feng and K. Müllen, J. Am. Chem. Soc., 2012, 134, 19532.

11 T. Zhang, M. Zheng, N. Li, H. Lu, S. Zhang and J. Cao, Mater. Lett., 2013, 105, 43.

12 K. Xia, Q. Gao, J. Jiang and J. Hu, Carbon, 2008, 46, 1718.

13 Q. Wang, J. Yan, Y. Wang, T. Wei, M. Zhang, X. Jing and Z. Fan, Carbon, 2014, 67, 119.

14 W. Xia, B. Qiu, D. Xia and R. Zou, Sci. Rep., 2013, 3, 1935.

15 T. Li, G. Yang, J. Wang, Y. Zhou and H. Han, J. Solid State Electrochem., 2013, 17, 2651.

16 W. Xing, C. C. Huang, S. P. Zhuo, X. Yuan, G. Q. Wang, D. Hulicova-Jurcakova, Z. F. Yan and G. Q. Lu, Carbon, 2009, 47, 1715.

17 Y. Lv, F. Zhang, Y. Dou, Y. Zhai, J. Wang, H. Liu, Y. Xia, B. Tu and D. Zhao, J. Mater. Chem., 2012, 22, 93.

18 Q. Zhao, T.-P. Fellinger, M. Antonietti and J. Yuan, Macromol. Rapid Commun., 2012, 33, 1149.

19 Y. Han, S. Liu, D. Li and X. Li, Electrochim. Acta, 2014, 138, 193.

20 X. Y. Chen, C. Chen, Z. J. Zhang and D. H. Xie, Ind. Eng. Chem. Res., 2013, 52, 12025.

21 J. Han, G. Xu, B. Ding, J. Pan, H. Dou and D. R. MacFarlane, J. Mater. Chem. A, 2014, 2, 5352.

22 W. Fan, Y.-Y. Xia, W. W. Tjiu, P. K. Pallathadka, C. He and T. Liu, J. Power Sources, 2013, 243, 973.

23 S. Wang, J. Zhang, P. Shang, Y. Li, Z. Chen and Q. Xu, Chem. Commun., 2014, 50, 12091.

24 N. P. Wickramaratne, J. Xu, M. Wang, L. Zhu, L. Dai and M. Jaroniec, Chem. Mater., 2014, 26, 2820.

25 F. Ma, H. Zhao, L. Sun, Q. Li, L. Huo, T. Xia, S. Gao, G. Pang, Z. Shi and S. Feng, J. Mater. Chem., 2012, 22, 13464.

26 X. Liu, L. Zhou, Y. Zhao, L. Bian, X. Feng and Q. Pu, ACS Appl. Mater. Interfaces, 2013, 5, 10280.

27 B. Xu, S. Yue, N. Qiao, M. Chu and G. Wei, Mater. Lett., 2014, 131, 49.

28 Q. Li, R. Jiang, Y. Dou, Z. Wu, T. Huang, D. Feng, J. Yang, A. Yu and D. Zhao, Carbon, 2011, 49, 1248.

29 D. Schaeffel, R. H. Staff, H. J. Butt, K. Landfester, D. Crespy and K. Koynov, Nano Lett., 2013, 12, 6012.

30 D. Crespy and K. Landfester, Soft Matter, 2011, 7, 11054.

31 D. Crespy and K. Landfester, Polymer, 2009, 50, 1616.

32 M. G. Schwab, D. Crespy, X. L. Feng, K. Landfester and K. Müllen, Macromol. Rapid Commun., 2011, 32, 1798.

33 R. Schiller, C. K. Weiss, J. Geserick, N. Husing and K. Landfester, Chem. Mater., 2009, 21, 5088.

34 J. Fickert, P. Rupper, R. Graf, K. Landfester and D. Crespy, J. Mater. Chem., 2012, 22, 2286.

35 G. Lota, B. Grzyb, H. Machnikowska, J. Machnikowski and

E. Frackowiak, Chem. Phys. Lett., 2005, 404, 53.

36 C.-T. Hsieh and H. Teng, Carbon, 2002, 40, 667.
37 K. Jurewicz, K. Babel, A. Źiółkowski and H. Wachowska, Electrochim. Acta, 2003, 48, 1491.

38 H. M. Jeong, J. W. Lee, W. H. Shin, Y. J. Choi, H. J. Shin, J. K. Kang and J. W. Choi, Nano Lett., 2011, 11, 2472.

39 W. Li, D. Chen, Z. Li, Y. Shi, Y. Wan, J. Huang, J. Yang, D. Zhao and Z. Jiang, Electrochem. Commun., 2007, 9, 569.

40 L. F. Chen, X.-D. Zhang, H.-W. Liang, M. Kong, Q.-F. Guan, P. Chen, Z.-Y. Wu and S.-H. Yu, ACS Nano, 2012, 6, 7092.

41 Z. S. Wu, W. C. Ren, L. Xu, F. Li and H. M. Cheng, ACS Nano, 2011, 5, 5463.

42 Z. S. Wu, A. Winter, L. Chen, Y. Sun, A. Turchanin, X. L. Feng and K. Müllen, Adv. Mater., 2012, 24, 5130.

43 K. Jurewicz, K. Babeł, A. Ziółkowski and H. Wachowska, J. Phys. Chem. Solids, 2014, 65, 269.

44 F. Béguin, K. Szostak, G. Lota and E. Frackowiak, Adv. Mater., 2005, 17, 2380.

45 E. Frackowiak, G. Lota, J. Machnikowski, C. Vix-Guterl and F. Béguin, Electrochim. Acta, 2006, 51, 2209.

46 Y. J. Kim, Y. Abe, T. Yanagiura, K. C. Park, M. Shimizu, T. Iwazaki, S. Nakagawa, M. Endo and M. S. Dresselhaus, Carbon, 2007, 45, 2116.

47 G. Lota, K. Lota and E. Frackowiak, Electrochem. Commun., 2007, 9, 1828.

48 D. Hulicova-Jurcakova, M. Kodama, S. Shiraishi, H. Hatori, Z. H. Zhu and G. Q. Lu, Adv. Funct. Mater., 2009, 19, 1800.

49 L. Wan, J. Wang, L. Xie, Y. Sun and K. Li, ACS Appl. Mater. Interfaces, 2014, 6, 15583.

50 W. H. Lee and J. H. Moon, ACS Appl. Mater. Interfaces, 2014, 6, 13968.

51 H. A. M. Biemans, C. Zhang, P. Smith, H. Kooijman, W. J. J. Smeets, A. L. Spek and E. W. Meijer, J. Org. Chem., 1996, 61, 9012.

52 K. I. Chane-Ching, J. C. Lacroix, R. Baudry, M. Jouini, S. Aeiyach, C. Lion and P. C. Lacaze, J. Electroanal. Chem., 1998, 453, 139.

53 M. Lazerges, M. Jouini, P. Hapiot, P. Guiriec and P.-C. Lacaze, J. Phys. Chem. A, 2003, 107, 5042.

54 S. Shrestha and W. E. Mustain, J. Electrochem. Soc., 2010, 157, 1665.

55 J. R. Pels, F. Kapteijn, J. A. Moulijn, Q. Zhu and K. M. Thomas, Carbon, 1995, 33, 1641.

56 S. Biniak, G. Szymański, J. Siedlewski and A. Światkowski, Carbon, 1997, 35, 1799.

57 Y. Tao, H. Kanoh, L. Abrams and K. Kaneko, Chem. Rev., 2006, 106, 896.

58 X. Yang, D. Wu, X. Chen and R. Fu, J. Phys. Chem. C, 2010, 114, 8581.

59 Z. Chen, J. Wen, C. Yan, L. Rice, H. Sohn, M. Shen, M. Cai, B. Dunn and Y. Lu, Adv. Energy Mater., 2011, 1, 551.

60 A. Vargová, K. Hrnčariková, D. Végh, V. Lukeš, P. Fedorko and P. Rapta, Electrochim. Acta, 2007, 52, 7885.

61 X. Hong, K. S. Hui, Z. Zeng, K. N. Hui, L. Zhang, M. Mo and M. Li, Electrochim. Acta, 2014, 130, 464. 